Былинская Наталья

кандидат психологических наук, доцент, заведующий кафедрой психологии

Брестского государственного университета им. А. С. Пушкина https://orcid.org/0000-0002-2545-5592

DOI https://doi.org/10.35619/praprv.v1i16.209

\title{
ИМПЛИЦИТНЫЕ ТЕОРИИ ЛИЧНОСТИ УЧЕНИКОВ, СУЩЕСТВУЮЩИХ В СОЗНАНИИ ПЕДАГОГОВ НАЧАЛЬНЫХ КЛАССОВ
}

\begin{abstract}
Аннотация. В настоящей статье излагаются результаты исследования имплицитных теорий личности (ИТЛ) школьников у педагогов начальных классов. Моделирование имплицитных теорий личности различных типов учащихся (нормального, трудного, одаренного и развивающегося) у учителей младщих классов, осуществленное посредством метода семантического дифференциала, показало их одинаковую когнитивную сложность для ученика нормального, проблемного, одаренного (пять ортогональных категорий). ИТЛ ученика развивающегося проще по своей структуре (четыре категории), что свидетельствует о меньшей знакомости для учителей данного типа учащихся. Общими категориями, опосредующими понимание учителями начальных классов различных типов учеников, являются: «ученический нонконформизм», «прилежание», «креативный лидер», "рациональный самоконтроль». Специифической категорией в ИТЛ проблемного ученика выступает конструкт «коммуникативное поведение», а в ИТЛ одаренного ученика - это конструкты «неординарность», «благополучная одаренность» $и$ «проблемная одаренность». Выявленная структура и содержание имплицитных теорий личности икольников свидетельствуют о недостаточной дифференциации знаний о личности различных типов учащихся в педагогическом сознании.
\end{abstract}

Ключевые слова: имплицитная теория личности, семантический дифференциал, факторный анализ, фактор, категория, конструкт.

Постановка проблемы. Имплицитные теории личности являются слабо рефлексируемыми или неосознаваемыми формами организации знаний субъекта о структуре и механизмах функционирования личности. Имплицитная теория личности складывается в индивидуальном опыте общения с людьми и становится достаточно устойчивой структурой, определяющей восприятие и понимание человека человеком. По мнению Андреевой, имплицитная теория личности (ИТЛ) выражается в обыденных представлениях, существующих у каждого человека, относительно связей между теми или иными качествами личности, ее структуры, а иногда и относительно мотивов поведения. Пользуясь данной теорией, индивид на основе определенного личностного качества, внешнего облика или поступка человека судит о его других возможных чертах личности, вероятных поступках и заранее настраивается на определенные формы поведения по отношению к этому человеку. Поскольку ИТЛ выполняют функцию ожиданий (адекватных и неадекватных) по отношению к другим людям и регулируют межличностное взаимодействие, в том числе и в системе «учитель - ученик», их изучение является актуальной практической задачей для более адекватной и полной реализации личностно-ориентированного подхода в образовании.

Анализ исследований по проблеме. Существующие в науке исследования имплицитных теорий личности школьников в основном представляют собой следующие три направления. К первой группе можно отнести эмпирические исследования, связанные с изучением имплицитных представлений педагогов об идеальном ребенке (Валитова, 1993; 
Котырло, 1987; Солодников, 1989; Харин, 1999). Исследования, относящиеся ко второму направлению, преимущественно связаны с изучением представлений о личности учащихся $c$ разными уровнями успеваемости (Бодалев, 1982; Кондратьева, 1980; Костюченко, 2008; Литаврина, 2003; Медведская, 2008). Исследования, относящиеся к третьему направлению, преимущественно связаны с изучением имплицитных представлений об одаренном ребенке (Былинская, 2011; Гусева, 2000; Carided, 2009). Обобщенный анализ результатов исследований ученых, направленных на изучение имплицитных теорий личности ребенка в педагогическом сознании, показал, что имплицитным теориям личности ребенка присущи следующие характеристики:

- неполнота знаний и стереотипность представлений педагогов о личности школьников;

- несоответствие эксплицитных психологических знаний реальным личностным качествам школьников;

- преобладание у педагогов оценочного, зачастую негативного отношения к ребенку;

- восприятие и понимание учащихся преимущественно в зависимости от их уровня академической успеваемости и особенностей поведения.

Авторы отмечают, что имплицитные теории личности ребенка, присутствующие в сознании учителей, являются важным регулятором педагогического взаимодействия. Посредством субъективных представлений и интуитивно созданных «теорий» учеников учитель организует собственную профессиональную деятельность, выбирая методы и приемы образования. Необходимо отметить, что педагог начальной школы является одной из первых инстанций, которая оценивает потенциал ребенка и создает ему соответствующие условия образования. Эта оценка производится на основе имеющихся у профессионала знаний. Профессиональная компетентность учителя, адекватность восприятия и понимания личности ученика, полнота знаний и представлений о его психологических особенностях позволяют объективно оценивать потенциал ребенка и создавать ему соответствующие условия образования. В последнее десятилетие в психолого-педагогической литературе для учителей достаточно активно предлагается разнообразный инструментарий, предназначенный для диагностики и сопровождения учащихся. Однако опыт работы с педагогами показывает, что реальная образовательная практика чаще базируется на субъективном восприятии и имплицитных, стереотипных представлениях педагогов о личности учеников.

Цель настоящего исследования заключалась в моделировании имплицитных теорий личности школьников, существующих в сознании педагогов начальной школы.

Изложение основного материала исследования. В качестве инструмента изучения знаний педагогов об учениках нами был использован один из самых информативных и универсальных методов исследования социальной перцепции - метод семантического дифференциала. В использованном в настоящем исследовании варианте семантического дифференциала эмпирическим материалом выступала 31 шкала, обозначающая различные личностные характеристики. При отборе шкал-дескрипторов было учтено несколько аспектов:

1. По результатам частотного анализа свободного описания учителями личности ученика были выделены те личностные характеристики, которые используются большинством педагогов для описания школьника.

2. Предлагаемые качества были сгруппированы по факторам, которые выделены в имплицитной теории личности, существующей в обыденном сознании. Поскольку содержание некоторых факторов оказалось практически отсутствующим в актуальном педагогическом словаре, он был дополнен наиболее весомыми характеристиками из тезауруса Шмелева (1991). Таким образом, семантический дифференциал включал в себя все шесть суперфакторов, обозначающих ведущие личностные категории в русскоязычной культуре.

3. Были заданы униполярные шкалы, так как их использование «... дает дополнительную «степень свободы» в проекции когнитивных структур испытуемых на 
экспериментальный материал, так как позволяет выделить субъективную синонимию и антонимию описываемых признаков, не обязательно совпадающую с нормативно-языковой» (Петренко, 2005).

В исследовании приняли участие 67 учителей начальных школ г. Бреста и Брестской области, педагогический стаж которых варьирует от 1 года до 30 лет.

По заданным шкалам педагогам начальной школы предлагалось оценить четыре типа учеников (нормальный, проблемный, одаренный, развивающийся) по 7-балльной шкале (от 1 до 7). Использование именно такой, более привычной для учителей шкалы продиктовано тем, что в пилотажном исследовании, работая с классической шкалой от -3 до 3 , некоторая часть педагогов испытывала затруднения при переходе от оценки позитивных к оценке негативных качеств.

Для моделирования имплицитных теорий личности школьника на основе индивидуальных протоколов проводилось построение матрицы сходства дескрипторов при оценке педагогами одного объекта (шкалы х испытуемые). Обработка исходных матриц осуществлялась посредством факторного анализа (центроидный метод с подпрограммой поворота факторных структур varimaks). Основаниями для отбора факторов стали: 1) значимость по критерию Кайзера и 2) неслучайность валентности для респондентов (т.е. превышение 5\%-го вклада в общий разброс значений). Интерпретация содержания выявленных факторов проводилась на основе имплицитной теории личности носителя русского языка Шмелева (1991).

В таблице 1 представлены усредненные оценки выраженности личностных качеств у разных типов учеников.

Таблица 1.

\section{Оценивание педагогами личностных качест различных типов учеников}

\begin{tabular}{|c|c|c|c|c|}
\hline \multirow{2}{*}{$\begin{array}{c}\text { Основные } \\
\text { разновидности } \\
\text { личностных } \\
\text { качеств }\end{array}$} & \multicolumn{4}{|c|}{$\begin{array}{c}\text { Оценки выраженности личностных качеств в учеников } \\
\text { разных типов }\end{array}$} \\
\hline & нормальнье & проблемные & одареннье & развиваюшчиеся \\
\hline усидчивость & 5,4 & 2,4 & 5,9 & 5,3 \\
\hline обучаемость & 5,59 & 2,94 & 6,33 & 5,88 \\
\hline активность & 5,43 & 3,81 & 6,22 & 5,52 \\
\hline общительность & 5,54 & 3,67 & 7,77 & 5,77 \\
\hline уравновешенность & 5,24 & 2,64 & 5,8 & 5,25 \\
\hline доброжелательность & 5,67 & 3,54 & 5,75 & 5,44 \\
\hline креативность & 4,7 & 2,97 & 6,25 & 5,25 \\
\hline трудолюбивость & 5,67 & 3,67 & 6 & 5,75 \\
\hline любознательность & 5,54 & 3,13 & 6,75 & 6 \\
\hline способность & 5,35 & 3,32 & 6,72 & 5,69 \\
\hline добросовестность & 5,48 & 3,35 & 6 & 5,75 \\
\hline необычность & 3,86 & 3,72 & 6,16 & 5,05 \\
\hline прилежность & 5,4 & 2,7 & 5,88 & 5,5 \\
\hline целеустремленность & 5,1 & 2,72 & 6,5 & 5,63 \\
\hline уверенность в себе & 4,97 & 3,29 & 6,05 & 5,19 \\
\hline инициативность & 4,94 & 2,72 & 6,08 & 5 \\
\hline любимчики & 4,24 & 2,43 & 5,11 & 4,75 \\
\hline лидерство & 4,32 & 2,86 & 5,3 & 4,63 \\
\hline воображение & 4,86 & 3,67 & 6,11 & 4,88 \\
\hline самоконтроль & 4,91 & 2,21 & 5,8 & 4,91 \\
\hline невнимательность & 2,67 & 3,81 & 2,66 & 2,91 \\
\hline злость & 1,89 & 4,1 & 2,27 & 2,27 \\
\hline
\end{tabular}

Випуск 16, 2021. Збірник наукових праць РдГУ 


\begin{tabular}{|l|l|l|l|l|}
\hline конфликтность & 2,24 & 4,72 & 2,41 & 2,33 \\
\hline неорганизованность & 2,13 & 4,48 & 2,52 & 2,13 \\
\hline неаккуратность & 2,02 & 4,4 & 2,33 & 2,55 \\
\hline неуправляемность & 1,78 & 4,94 & 1,86 & 2,33 \\
\hline забывчивность & 2,4 & 4,21 & 2,77 & 2,55 \\
\hline $\begin{array}{l}\text { отклонения в } \\
\text { психофизиол. развитии }\end{array}$ & 1,32 & 4,21 & 1,69 & 1,63 \\
\hline импульсивность & 2,37 & 4,91 & 3,3 & 2,47 \\
\hline недисциплинированность & 1,89 & 5,18 & 2,25 & 2,11 \\
\hline агрессивность & 1,86 & 4,62 & 1,86 & 2,02 \\
\hline
\end{tabular}

Первичная обработка усредненных оценок личностных качеств изучаемых типов учеников не выявила между ними достоверных отличий (нормальный и проблемный ученик $\mathrm{t}$ $=1,178$; нормальный и одаренный $\mathrm{t}=0,102$; нормальный и развивающийся $\mathrm{t}=0,53$; проблемный и развивающийся $\mathrm{t}=0,035$; проблемный и одаренный $\mathrm{t}=0,002$; одаренный и развивающийся $\mathrm{t}=0,277$, при критическом $\mathrm{t}=2,02$ для $\mathrm{p} \leq 0,05)$. График наглядно демонстрирует, что конфигурации линий оценок личностных качеств ученика нормального (ряд 1), развивающегося (ряд 4) и одаренного (ряд 3) фактически совпадают друг с другом.

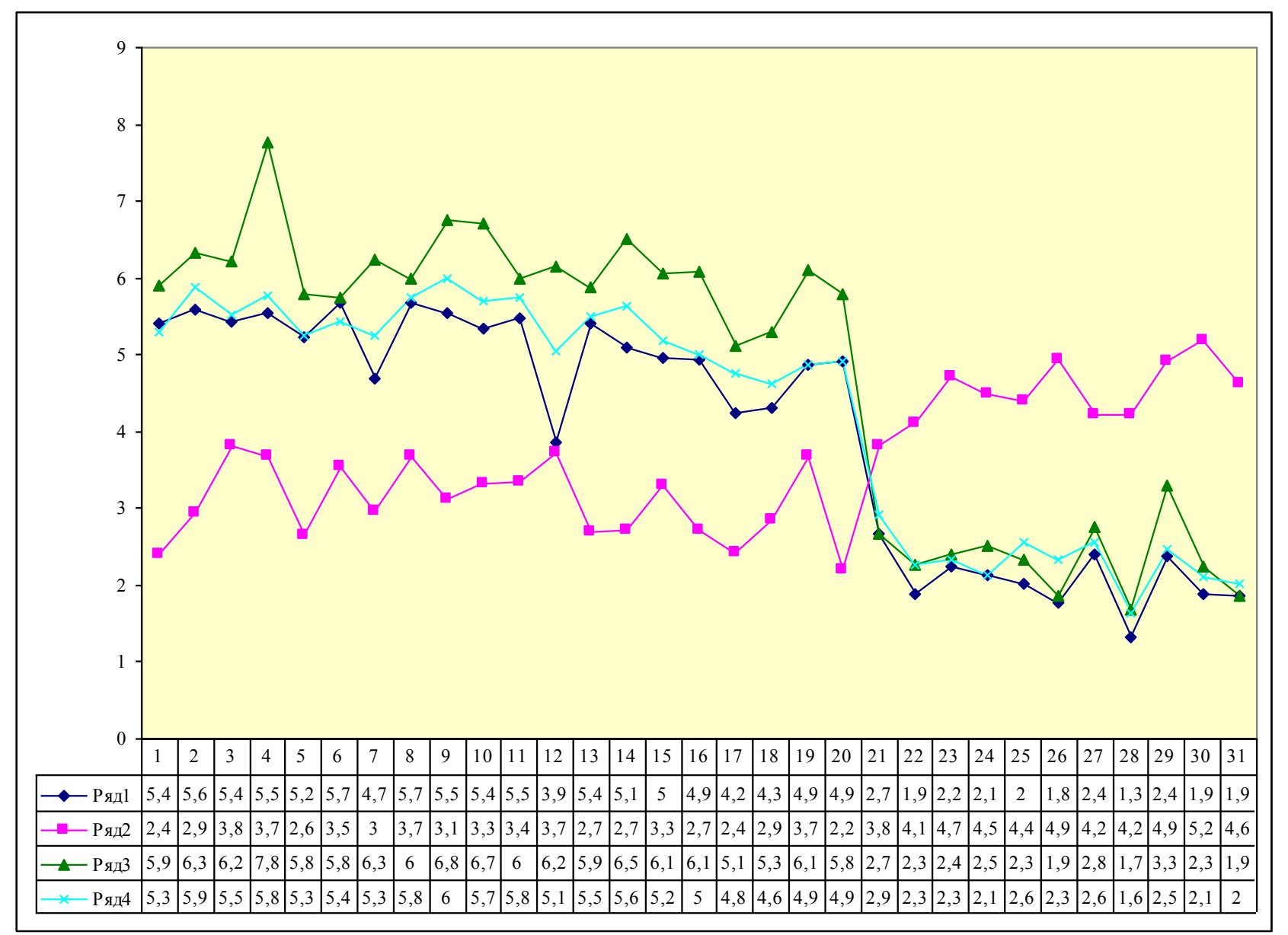

\section{Рис. 1. Показатели средних оценок личности ученика}

Высокие оценки названным типам учеников учителя поставили по следующим качествам: усидчивый (1), обучаемый (2), активный (3), общительный (4), трудолюбивый (8); и низкие показатели по таким качествам как: злой (22), конфликтный (23), неаккуратный (25), недисциплинированный (30). Отличие состоит в том, что у ученика одаренного качества 
общительный (4), креативный (7), необычный (12), целеустремленный (14), воображение (19) более развиты, чем у ученика нормального и развивающегося.

График, расположенный на рисунке 1, наглядно демонстрирует, что у проблемных учеников (ряд 2) менее всего, по мнению учителей, развиты такие качества, как усидчивость (1), обучаемость (2), уравновешенность (5), креативность (7), прилежание (13), целеустремленность (14), самоконтроль (20). У данного типа школьников выявлены высокие показатели средних значений по следующим качествам личности: невнимательный (21), злой (22), конфликтный (23), неорганизованный $(24), \quad$ неуправляемый $\quad(26), \quad$ с психофизиологическими отклонениями (28), недисциплинированный (30), агрессивный (31). Таким образом, относительно трудных, проблемных учеников выделена такая же переоценка негативных личностных качеств, которая присутствует и в учащихся с низким уровнем успеваемости.

Выводы из данного исследования. Факторизация исходных матриц данных позволила выявить категории-обобщения, образующие имплицитные теории личности нормального, проблемного, одаренного и развивающегося учеников.

ИТЛ нормального ученика. В итоге факторного анализа первичной матрицы в группе педагогов было выделено пять независимых факторов.

Первый по мощности фактор (28\% общей дисперсии) представлен шкалами: неорганизованный (0,878), злой $(0,873)$, импульсивный $(0,844)$, конфликтный $(0,844)$, неуправляемый $(0,830)$, агрессивный $(0,824)$, забывчивый $(0,746)$, неаккуратный $(0,683)$. В содержании ведущей категории, опосредующей понимание учителями личности нормального ученика, оказались соединены различные негативные качества, заданные в семантическом дифференциале. Это говорит о том, что обычный школьник воспринимается как некий противостоящий педагогу субъект. В целом выделенную категорию можно обозначить как «ученический нонконформизм». Следует также отметить, что по своему содержанию и по своей валентности она в основном соответствует категории «аморальность», выделенной в качестве основной категории в понимании педагогами учащихся с различными уровнями успеваемости в исследованиях Медведской (2008), хотя в настоящем исследовании были заданы и другие объекты оценивания, и другие шкалыдискрипторы семантического дифференциала. Думается, что выделение данной категории в качестве ведущей и есть конкретное воплощение воспитательной позиции, опирающейся на концепцию зла в ребенке, «выкорчевать которое и есть добро воспитания. В этой корчующей педагогике ребенок, из субъекта социального взаимодействия, превращается в объект воздействия, манипулирования. Вместо воспитания навыков опрятности и личной гигиены борьба с нечистоплотностью, вместо воспитания щедрости - борьба с жадностью и т.П.» (Каган, 1992).

Второй фактор (18 \% общей дисперсии) образован шкалами: самоконтроль $(0,849)$, любимчик (0,833), лидер (0,717), необычный $(0,706)$, воображение $(0,692)$, общительный (0,512). Содержание этого фактора можно обозначить как «креативный лидер», который, по мнению респондентов, способен к самоконтролю и легко находит общий язык, как со сверстниками, так и с взрослыми.

Третий по мощности фактор (7,3\% общей дисперсии) образован следующими шкалами: добросовестный (0,826), любознательный $(0,757)$, трудолюбивый $(0,713)$. Содержание этого фактора в основном совпадает с четвертым фактором в имплицитной концепции личности Шмелева - «рациональный самоконтроль».

Четвертый фактор (5,9\% общей дисперсии) включает в себя шкалы: активный (0,690), инициативный (0,682), целеустремленный (0,615), уверенный $(0,503)$. Данная категория соответствует третьему фактору в имплицитной теории личности Шмелева «актуальная энергия».

Пятый фактор (5,7\% общей дисперсии) представлен шкалами: обучаемылй (0,783), уравновешенный (0,572), прилежный $(0,526)$. Этот фактор демонстрирует понимание нормального ученика как уравновешенного, способного к обучению субъекта учебновоспитательного процесса. В целом выделенную категорию можно назвать «прилежание». 
ИТЛ проблемного, трудного ученика. Факторный анализ общегрупповой матрицы данных также выявил пять ортогональных факторов-категорий.

Первый по мощности фактор (29\% общей дисперсии) представлен шкалами: неуправляемый (0,883), психофизическое отклонение $(0,852)$, злой $(0,783)$, импульсивный (0,773), недисииплинированный $(0,768)$, агрессивный $(0,767)$, конфликтный $(0,716)$, неорганизованный $(0,698)$, забывчивый $(0,603)$, неаккуратный $(0,580)$, усидчивый $(-0,557)$. Содержание выделенной категории в основном совпадает с ведущей категорий в ИТЛ нормального ученика, обозначенной выше как «ученический нонконформизм». Выделение этого конструкта, в качестве ведущего, демонстрирует негативное отношение учителей начальной школы к проблемным учащимся. Это можно объяснить тем, что трудные школьники, по мнению респондентов, создают помехи нормальному протеканию учебновоспитательного процесса. Кроме того, часто проблемные дети социально дезадаптированы, психофизиологически нездоровы. Эти особенности данного типа учащихся известны учителям, о чем говорит появление в содержании данного конструкта специфического дискриптора - психофизиологическое отклонение, имеющего большую нагрузку по этому фактору.

Второй по мощности фактор (20,7\% общей дисперсии) образован шкалами: уверенный (0,845), инициативный $(0,835)$, иелеустремленный $(0,712)$, любознательный (0,655), самоконтроль (0,639), способный $(0,622)$, добросовестный $(0,575)$, прилежный (0,511). В содержании данной категории соединены характеристики ученического прилежания и показатели активности ребенка, что соответствует третьему фактору в имплицитной концепции личности Шмелева - «актуальная энергия».

Третий фактор (6,58\% общей дисперсии) включает в себя шкалы: любимчик $(0,772)$, трудолюбивый (0,593), доброжелательный $(0,566)$. Этот конструкт можно обозначить как «старательность». По мнению респондентов, проблемный ученик, отличающийся трудолюбием, старанием и доброжелательным отношением к другим, заслуживает уважения и симпатии.

Четвертая категория (6,47\% общей дисперсии) представлена шкалами: лидер $(0,758)$, креативный $(0,719)$, воображение $(0,561)$. Эта категория также уже встречалась в описании личности нормального ученика и обозначалась как «креативный лидер».

Пятый фактор (5,12\% общей дисперсии) образован шкалами: общительный $(0,779)$, активный (0,758), уравновешенный (0,552). Этот фактор является самым слабым по мощности, его можно назвать «коммуникативное поведение».

ИТЛ одаренного ученика. В результате факторного анализа исходной матрицы было выделено пять независимых категорий, образующих имплицитную теорию личности одаренного ученика.

Первыци по мощности фактор (33,15\% общей дисперсии) образован шкалами: целеустремленный $(0,836)$, креативный $(0,807)$, способный $(0,799)$, любознательный $(0,772)$, воображение $(0,757)$, необычный $(0,671)$, трудолюбивый $(0,577)$, инициативный $(0,573)$, добросовестный $(0,550)$, прилежный $(0,506)$. Содержание этого фактора можно обозначить «необычный, неординарный ученик». Выделение данной категории, в качестве ведущей свидетельствует о наличии у педагогов начальной школы научных представлений о личностных характеристиках одаренных учеников.

Второй фактор (18,81\% общей дисперсии) представлен шкалами: злой $(0,871)$, конфликтный (0,863), неуправляемый (0,827), невнимательный (0,779), неаккуратный (0,778), неорганизованный $(0,700)$. Подобный конструкт уже обозначался выше как «ученический нонконформизм».

Третий фактор (8,4\% общей дисперсии) включает в себя шкалы: любимчик $(0,909)$, лидер (0,860), доброжелательный (0,797), уравновешенный $(0,779)$, самоконтроль $(0,571)$. Содержание этого фактора можно обозначить «благополучная одаренность», которая обеспечивает не только личный успех способного ученика, но и успех общественный: педагога, класса, школы и т.д. 
Четвертый фактор (6,3\% общей дисперсии) образован шкалами: обучаемый $(0,845)$, активный $(0,744)$, усидчивый $(0,742)$, уверенный $(0,466)$. Данная категория уже фиксировалась как «прилежание».

Пятый по мощности фактор (5,49\% общей дисперсии) представлен шкалами: агрессивный (0,852), забывчивый (0,681), психофизиологическое отклонение $(0,674)$, недисииплинированный $(0,498)$. Содержание этой категории демонстрирует существующее у педагогов начальных классов мнение о том, что проявление творческого потенциала и интеллектуальных способностей можно наблюдать у разных учеников, в том числе у проблемных, дезадаптивных детей с асоциальным и девиантным поведением. Данный конструкт можно назвать «проблемная одаренность».

ИТЛ развивающегося ученика. В итоге факторного анализа исходной матрицы данных в группе педагогов начальной школы было выделено четыре независимых фактора.

Первый по мощности фактор (40\% общей дисперсии) представлен шкалами: лидер (0,921), воображение (0,921), инициативный $(0,865)$, самоконтроль $(0,860)$, любимчик $(0,833)$, активный $(0,791)$, способный $(0,775)$, уверенный $(0,756)$, необычный $(0,748)$, общительный (0,704), креативный (0,701), любознательный $(0,651)$, обучаемый $(0,646)$, доброжелательный $(0,611)$. Выделение данной категории, в качестве ведущей является вполне закономерным в контексте приоритета личностно-ориентированных образовательных моделей. По мнению учителей, развивающийся ученик должен обладать не только интеллектуальным потенциалом, но и нравственными качествами, которые способствуют становлению толерантной, креативной, саморазвивающейся личности. Этот конструкт уже встречался при описании одаренного ученика и был обозначен как «необычный, неординарный ученик».

Второй по мощности фактор (22\% общей дисперсии) включает в себя шкалы: неуправляемый (0,895), недисциплинированный (0,872), неаккуратный $(0,842)$, неорганизованный $(0,819)$, забывчивый $(0,790)$, агрессивный $(0,773)$, импульсивный $(0,750)$, невнимательный $(0,735)$. Подобный конструкт ранее обозначался как «ученический нонконформизм».

Третий фактор (6\% общей дисперсии) образован шкалами: усидчивый $(0,773)$, трудолюбивый $(0,605)$, злой $(0,520)$, конфликтный $(0,390)$, психофизиологическое отклонение $(0,379)$. В содержании выделенной категории обращает на себя внимание ее противоречивость, алогичность. По ведущим шкалам данная категория может быть зафиксирована как и ранее «рациональный самоконтроль».

Четвертый фактор (5\% общей дисперсии) представлен шкалами: прилежный $(0,811)$, целеустремленный (0,716), уравновешенный (0,393), добросовестный $(0,457)$. Содержание этого фактора можно обозначить «прилежание». Данный конструкт содержит наиболее значимые качества ученика начальной школы, которые способствуют обучению и личностному развитию учащегося.

В заключение необходимо отметить, что для оценки устойчивости полученных факторных решений использовался психометрический прием «расщепления выборки пополам», т.е. факторизация исходных матриц проводилась также и отдельно для случайных групп респондентов (n=34). Для ведущего фактора «ученический нонконформизм», образующих имплицитную теорию личности нормального и трудного учеников средняя величина коэффициента корреляции Спирмена, полученная при попарном сопоставлении факторных матриц внутри двух подгрупп педагогов, имеет высокие значения: от 0,83 до 0,86. Для ведущих факторов, образующих ИТЛ одаренного и развивающегося школьников аналогичные коэффициенты расположены в диапазоне от 0,32 до 0,65 . Имеющиеся исследования Петренко (2005) и Шмелева (1991), позволяют считать, что коэффициент конгруэнтности не ниже 0,8 свидетельствует об идентичности факторов или о высокой внутригрупповой согласованности респондентов, в силу чего результаты среднегрупповой матрицы могут репрезентировать всю выборку в целом. Иначе говоря, выявленная категория «ученический нонконформизм» может быть перенесена на генеральную совокупность 
учителей, а категория «необычный ученик» является выражением только частного случая понимания, присущего именно нашим респондентам.

Таким образом, проведенное моделирование имплицитной теории личности различных категорий учеников позволяет сделать следующие основные выводы.

1. Показатели средних значений по качествам личности у ученика нормального, одаренного и развивающегося практически аналогичны. Высокие показатели по качествам: усидчивый, обучаемый, общительный, активный, трудолюбивый; и низкие по качествам: злой, конфликтный, недисциплинированный и неаккуратный. Отличие состоит в том, что у одаренного ученика, по мнению учителей, более выражены такие качества как: целеустремленный, необычный, креативный, общительный.

2. У трудных, проблемных учеников выявлены высокие показатели средних значений по следующим качествам личности: злой, невнимательный, конфликтный, неорганизованный, неуправляемый, с психофизиологическими отклонениями, агрессивный, что соответствует феномену субъективизма педагогической оценки личности школьника с низким уровнем успеваемости. Такие качества личности как усидчивость, прилежание, самоконтроль, креативность данному типу учащихся присущи в меньшей степени, чем нормальному, одаренному и развивающемуся ученику.

Моделирование имплицитных теорий показало их одинаковую когнитивную сложность для ученика нормального, проблемного, одаренного (пять ортогональных категорий). ИТЛ ученика развивающегося немного проще по своей структуре (четыре категории), что свидетельствует о меньшей знакомости для учителей данного типа учащихся.

3. Среди выделенных категорий-обобщений в различных ИТЛ есть общие и специфические. Так, общими категориями, опосредующими понимание учителями начальных классов различных типов учеников, являются: «ученический нонконформизм», «прилежание», «креативный лидер», «рациональный самоконтроль». Специфической категорией в имплицитной теории личности проблемного ученика выступает конструкт «коммуникативное поведение», а в ИТЛ одаренного ученика - это конструкты «неординарность», «благополучная одаренность» и «проблемная одаренность».

4. Выявленная структура и содержание имплицитных теорий личности школьников позволяют говорить о недостаточной дифференциации знаний о личности различных типов учащихся в педагогическом сознании.

\section{СПИСОК ССЫЛОК}

Андреева, Г. М. (2000). Сочиальная психология. Москва: Аспект Пресс.

Бодалев, А. А. (2012). Восприятие и понимание человеком человека. Москва: Книга по Требованию.

Былинская, Н. В. (2011). Обычный и одаренный ученики: имплицитные теории личности в педагогическом сознании. Психология обучения, 2, 96-109.

Валитова, И. Е. (1993). Содержание имплицитной педагогической концепции воспитателей дошкольных учреждений. Психологическая наука и общая практика. Минск: МГПУ им. М. Танка.

Гусева, С. И. (2000). Образ математически одаренного ученика в сознании педагога. (Дис. канд. психол. наук). Ленинградский государственный университет имени А. С. Пушкина. Санкт-Петербург.

Каган, В. Е. (1992). Тоталитарное сознание и ребенок: семейное воспитание. Bопросы психологии, 1-2, 14-21.

Кондратьева, С. В. (1980). Понимание учителем личности учащегося. Вопросы психологии, 5 , 143-148.

Костюченко, Е. В. (2008). Когнитивная сложность учителя и ее проявление в педагогической социальной перцепции. Актуальные проблемы современной психологии. 
Котырло, В. К. (1987). Формирование взаимоотношений дошкольников в детском саду и семье. Москва: Педагогика.

Литаврина, О. Б., Панкина В. В., \& Кондаков, И. М. (2003). Исследование особенностей “имплицитных теорий личности” в школьном возрасте. Психологическая наука и образование, 3, 34-42.

Медведская, Е. И. (2008). Психосемантика понимания учителем личности ученика. Брест: БрГУ.

Солодников, В. В. (1989). Идеальный ребенок в представлении педагогов. Социологические исследования, 4, 87-91.

Петренко, В. Ф. (2005). Основы психосемантики. Санкт-Петербург: Питер.

Харин, С. С. (1999). Психологические основь формирования у педагогов личностноориентированного подхода к ребенку. Минск: Академия последипломного образования.

Шмелев, А. Г. (1983). Введение в экспериментальную психосемантику: теоретикометодологические основания и психодиагностические возможности. Москва: МГУ.

Carided, G. M., Coach, M., \& Betsy, M. D. (2009). Educators Implicit Theories of Intelligence and Beliefs about the Identification of Gifted Students. Universitas Psychologica, Pontificia Universided Javeriana Colombia, 8, 295-310.

\section{REFERENCES}

Andreeva, G. M. (2000). Social'naya psihologiya [Social psychology]. Moskva: Aspekt Press. [in Russian].

Bodalev, A. A. (1982). Vospriyatie i ponimanie chelovekom cheloveka [Perception and understanding of the human person]. Moskva: MGU. [in Russian].

Bylinskaya, N. V. (2011). Obychnyj i odarennyj ucheniki: implicitnye teorii lichnosti v pedagogicheskom soznanii [Ordinary and gifted students: implicit theories of personality in the pedagogical consciousness]. Psihologiya obucheniya, 2, 96-109. [in Russian].

Valitova, I. E. (1993). Soderzhanie implicitnoj pedagogicheskoj kon-cepcii vospitatelej doshkol'nyh uchrezhdenij [The content of the implicit pedagogical concept of preschool educators]. Psihologicheskaya nauka i ob-shchaya praktika. Minsk: MGPU im. M. Tanka. [in Russian].

Guseva, S. I. (2000). Obraz matematicheski odarennogo uchenika v soznanii pedagoga [The image of a mathematically gifted student in the mind of a teacher]. (Dis. Kand. psihol. nauk). Leningrad State University named after A. S. Pushkin. Sankt-Peterburg. [in Russian].

Kagan, V. E. (1992). Totalitarnoe soznanie i rebenok: semejnoe vospitanie [Totalitarian consciousness and the child: family education]. Voprosy psihologii, 1-2, 14-21. [in Russian].

Kondrat'eva, S. V. (1980). Ponimanie uchitelem lichnosti uchashchegosya [The teacher's understanding of the student's personality]. Voprosy psihologii, 5, 143-148. [in Russian].

Kostyuchenko, E. V. (2008). Kognitivnaya slozhnost' uchitelya i ee proyavlenie v pedagogicheskoj social'noj percepcii [Cognitive complexity of the teacher and its manifestation in pedagogical social perception]. Aktual'nye problemy sovremennoj psihologii. Grodno: GrGU. [in Russian].

Kotyrlo, V. K. (1987). Formirovanie vzaimootnoshenij doshkol'nikov v detskom sadu i sem'e [Formation of relationships between preschoolers in kindergarten and family]. Moskva: Pedagogika. [in Russian].

Litavrina, O. B., Pankina, V. V., \& Kondakov, I. M. (2003). Issledovanie osobennostej "implicitnyh teorij lichnosti" v shkol'nom vozraste [Study of the features of "implicit theories of personality" at school age]. Psihologicheskaya nauka i obrazovanie, 3, 34-42. [in Russian].

Medvedskaya, E. I. (2008). Psihosemantika ponimaniya uchitelem lichnosti uchenika [Psychosemantics of the teacher's understanding of the student's personality]. Brest: BrGU.

Solodnikov, V. V. (1989). Ideal'nyj rebenok v predstavlenii pedagogov [The ideal child in the minds of educators]. Sociologicheskie issledovaniya, 4, 87-91. [in Russian].

Petrenko, V. F. (2005). Osnovy psikhosemantiki [Basic principles of psychosemantics]. SanktPeterburg: Piter. [in Russian]. 
Harin, S. S. (1999). Psihologicheskie osnovy formirovaniya u pedagogov lichnostnoorientirovannogo podhoda $k$ rebenku [Psychological foundations of the formation of a personality-oriented approach to a child in teachers]. Minsk: Akademiya poslediplomnogo obrazovaniya. [in Russian].

Shmelev, A. G. (1983). Vvedeniye $v$ eksperimentalnuyu psikhosemantiku: teoretikometodologicheskiye osnovaniya $i$ psikhodiagnosticheskiye vozmozhnosti [Introduction to experimental psychosemantics: theoretical and methodological grounds and psychodiagnostic capabilities]. Moskva: MGU. [in Russian].

Carided, G. M., Coach, M., \& Betsy, M. D. (2009). Educators Implicit Theories of Intelligence and Beliefs about the Identification of Gifted Students. Universitas Psychologica, Pontificia Universided Javeriana Colombia, 8, 295-310. [in English].

\title{
IMPLICIT THEORIES OF STUDENTS' PERSONALITIES EXISTING IN THE MINDS OF PRIMARY SCHOOL TEACHERS
}

\author{
Natalia Bylinskaya \\ Candidate of Psychological Sciences, Associate Professor \\ of department of Psychology of the \\ Brest State A.S. Pushkin University, \\ https://orcid.org/0000-0002-2545-5592
}

DOI https://doi.org/10.35619/praprv.v1i16.209

\begin{abstract}
This article presents the results of research of the implicit personality theory of schoolchildren among primary school teachers. Modeling of implicit personality theory of various types of students (normal, difficult, gifted and developing) among primary school teachers, carried out using the semantic differential method, showed their identical cognitive complexity for a normal, problematic, gifted student (five orthogonal categories).

The implicit personality theory of a developing student is simpler in structure (four categories), which indicates less familiarity for teachers of this type of students. The general categories that mediate the understanding by primary school teachers of various types of students are: "student non-conformism», "diligence», "creative leader», "rational self-control». A specific category in the implicit personality theory of a problem student is the construct "communicative behavior», and in the implicit personality theory of a gifted student are the constructs «eccentricity», "prosperous giftedness» and «problematic giftedness».

The revealed structure and content of implicit personality theory of schoolchildren indicate insufficient differentiation of knowledge about the personality of various types of students in the pedagogical consciousness.
\end{abstract}

Key words: implicit personality theory, semantic differential, factor analysis, factor, category, construct. 